\title{
Maternal Thrombophilia and Recurrent Miscarriage - Is There Evidence That Heparin is Indicated as Prophylaxis against Recurrence?
}

\section{Mütterliche Thrombophilie und wiederholte Fehlgeburten - gibt es eine evidenzbasierte Indikation für Heparin als Rezidivprophylaxe?}

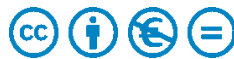

Authors

Ana-Luisa Stefanski ${ }^{1,2}$, Christoph Specker ${ }^{3}$, Rebecca Fischer-Betz ${ }^{4}$, Wolfgang Henrich ${ }^{5}$, Ekkehard Schleussner ${ }^{6 *}$, Thomas Dörner ${ }^{*}$

Affiliations

1 Zentrum Innere Medizin, Medizinische Klinik mit Schwerpunkt Rheumatologie und Klinische Immunologie, Charité Berlin, Berlin, Germany

2 Rheumatologie, klinische Immunologie und Allergologie, Inselspital Universitätsspital Bern, Bern, Switzerland

3 Krankenhaus St. Josef, Klinik für Rheumatologie und klinische Immunologie, Universitätsklinikum Essen, Essen, Germany

4 Poliklinik für Rheumatologie, Schwangerschaftsambulanz, Heinrich-Heine-Universität Düsseldorf Medizinische Fakultät, Düsseldorf, Germany

5 Klinik für Geburtsmedizin, Charité Berlin, Berlin, Germany

6 Klinik für Geburtshilfe, Universitätsklinikum Jena, Jena, Germany

Key words

loss of pregnancy, preeclampsia, pregnancy

Schlüsselwörter

Abort, Präeklampsie, Schwangerschaft

received 23.10.2017

revised $\quad 15.1 .2018$

accepted 15.1.2018

Bibliography

DOI https://doi.org/10.1055/s-0044-100919

Geburtsh Frauenheilk 2018; 78: 274-282 @ Georg Thieme

Verlag KG Stuttgart · New York | ISSN 0016-5751

Correspondence

Dr. Ana-Luisa Stefanski, Dr. med.

Charité Berlin, Zentrum Innere Medizin, Medizinische Klinik mit Schwerpunkt Rheumatologie und Klinische Immunologie Charitéplatz 1, 10117 Berlin, Germany

ana-luisa.stefanski@charite.de
Deutsche Version unter:

https://doi.org/10.1055/s-0044-100919

\section{ABSTRACT}

Background Recurrent miscarriage, also referred to as recurrent spontaneous abortion (RSA), affects $1-5 \%$ of couples and has a multifactorial genesis. Acquired and congenital thrombophilia have been discussed as hemostatic risk factors in the pathogenesis of RSA.

Method This review article was based on a selective search of the literature in PubMed. There was a special focus on the current body of evidence studying the association between RSA and antiphospholipid syndrome and hereditary thrombophilia disorders.

Results Antiphospholipid syndrome (APS) is an acquired autoimmune thrombophilia and recurrent miscarriage is one of its clinical classification criteria. The presence of lupus anticoagulant has been shown to be the most important serologic risk factor for developing complications of pregnancy. A combination of low-dose acetylsalicylic acid and heparin has shown significant benefits with regard to pregnancy outcomes and APS-related miscarriage. Some congenital thrombophilic disorders also have an increased associated risk of developing RSA, although the risk is lower than for APS. The current analysis does not sufficiently support the analogous administration of heparin as prophylaxis against miscarriage in women with congenital thrombophilia in the same way as it is used in antiphospholipid syndrome. The data on rare, combined or homozygous thrombophilias and their impact on RSA are still insufficient.

Conclusion In contrast to antiphospholipid syndrome, the current data from studies on recurrent spontaneous abortion

* Shared last authorship 
do not support the prophylactic administration of heparin to treat women with maternal hereditary thrombophilia in subsequent pregnancies. Nevertheless, the maternal risk of thromboembolic events must determine the indication for thrombosis prophylaxis in pregnancy.

\section{ZUSAMMENFASSUNG}

Hintergrund Wiederholte Fehlgeburten, auch wiederholte Spontanaborte (WSA) genannt, werden von 1-5\% der Paare erlebt und weisen eine multifaktorielle Genese auf. Erworbene und angeborene Thrombophilien werden als hämostaseologische Risikofaktoren in der Pathogenese diskutiert.

Methode Die Übersichtsarbeit basiert auf einer selektiven Literaturrecherche in PubMed. Auf die aktuelle Evidenzlage zu WSA beim Antiphospholipidsyndrom und den hereditären Thrombophilien wird besonders hingewiesen.

Ergebnisse Das Antiphospholipidsyndrom (APS) ist eine erworbene, autoimmun-vermittelte Thrombophilie, bei der wiederholte Fehlgeburten zu den klinischen Klassifikationskriterien gehören. Von den serologischen Kriterien hat sich der
Nachweis des Lupusantikoagulans als wichtigster Risikofaktor für die Entwicklung von Schwangerschaftskomplikationen herauskristallisiert. Der kombinierte Einsatz von niedrigdosiertem ASS mit Heparin zeigte einen deutlichen Vorteil hinsichtlich des Schwangerschaftsausgangs bei APS-bedingten Fehlgeburten. Bei einigen angeborenen Thrombophilien besteht auch eine erhöhte Risikoassoziation mit der Entstehung von WSA, wenn auch geringer als beim APS. Der Analogschluss zum Antiphospholipidsyndrom bezüglich des Einsatzes von Heparin zur Abortprophylaxe wird durch die aktuellen Analysen nicht hinreichend unterstützt. Daten zu seltenen, kombinierten bzw. homozygoten Thrombophilien bez. Fehlgeburten sind unzureichend.

Schlussfolgerung Anders als beim Antiphospholipidsyndrom stellen wiederholte Spontanaborte für sich bei mütterlicher hereditärer Thrombophilie nach aktueller Studienlage keine Indikation zur prophylaktischen Heparingabe in einer Folgeschwangerschaft dar. Unabhängig davon bestimmt das maternale Risiko für thromboembolische Ereignisse die Indikation für eine Thromboseprophylaxe in der Schwangerschaft.

\section{Recurrent Spontaneous Abortion}

Pregnancy loss, defined as spontaneous loss of the fetus before the end of the 24th week of gestation (GW), is the most common complication of pregnancy worldwide [1]. Around 15\% of clinical pregnancies end by spontaneous abortion. It is estimated that almost every second woman will have at least one miscarriage during her reproductive years. Recurrent spontaneous abortion (RSA) is reported for around $1-5 \%$ of couples [2]. The figures vary, depending on the diagnostic criteria used to define RSA; while the WHO definition stipulates three or more consecutive miscarriages before the end of the 20th completed week of gestation [1], the American guidelines define RSA as two failed intrauterine pregnancies [3]. Recurrent spontaneous abortion has a multifactorial pathogenesis which often remains unexplained [4], and it represents a clinical challenge, both for the affected women and their treating physicians.

In addition to morphological, hormone-related and genetic causes, thrombophilic disorders have also been discussed as hemostatic risk factors for RSA. Thrombophilic disorders are a group of genetically determined or acquired hemostatic disorders which are associated with an increased propensity for venous thromboembolism (VTE). Antiphospholipid syndrome is considered to be a serious acquired thrombophilic disorder.

This review article examines the current body of literature on RSA in antiphospholipid syndrome and hereditary thrombophilias and the diagnostic and therapeutic recommendations in the German and international literature.

\section{Complications of Pregnancy and Antiphospholipid Syndrome}

Antiphospholipid syndrome (APS) is an autoantibody-mediated acquired thrombophilia of unclear etiology. Serologic criteria for APS include persistent detection of medium to high-titer autoantibodies against anionic phospholipids such as cardiolipin and $\beta 2$-glycoprotein I or positive lupus anticoagulant (LA). The titer must be unambiguously positive when measured twice at an interval of at least 12 weeks between measurements, because infections and injuries etc. can temporarily lead to false-positive antibody results. Lupus anticoagulant can be false-positive following already initiated therapy with heparins, vitamin-K antagonists or the new oral anticoagulants [5].

The Sydney classification criteria of 2006 state that in addition, at least one clinical criteria must be fulfilled for a diagnosis of APS to be made; clinical criteria can include thromboembolic events and defined complications of pregnancy ( $\bullet$ Table 1 ) [6]. If all three serologic APS criteria (cardiolipin and $\beta 2$-glycoprotein I antibodies as well as LA) are met, this is referred to as triple positivity. Patients with triple positivity have the highest risk of developing the clinical manifestation of APS. In some rare cases these autoantibodies are detected in the context of other autoimmune diseases, usually in patients with systemic lupus erythematosus (SLE), which is then referred to as associated or secondary APS. If no underlying collagenosis is present, it is known as primary APS. The data on the relationship between primary and associated APS varies widely. Depending on the stringency of the diagnosis, up to $40 \%$ of APS patients also present with the clinical manifestations of SLE [7].

Irrespective of any VTE manifestations, up to $90 \%$ of patients with untreated APS had an obstetric history of miscarriage $[7,8]$. 
Particularly pregnancy losses in the second trimester of pregnancy and severe preeclampsia appear to be strongly associated with APS $[9,10]$. In addition to recurrent spontaneous abortion, APS is associated with a number of other complications of pregnancy which are characterized by disordered placental development and consequent functional placental insufficiency. This includes primarily late spontaneous abortions and intrauterine fetal death, intrauterine growth restriction of the fetus (IUGR), preeclampsia and premature placental separation. Because of the different classification criteria, study designs and investigated populations, it is difficult to estimate the incidence of these complications of pregnancy in APS.

Conversely, antiphospholipid antibodies or LA have been detected in around $6 \%$ of women with these complications of pregnancy [11]. The presence of lupus anticoagulant has been determined to be the most important risk factor $[12,13]$. The following factors for high-risk pregnancies were additionally identified:

- previous VTE or complications of pregnancy in a previous pregnancy (OR 12.7),

- triple positivity (OR 9.2), or

- associated APS with clinically manifest SLE (OR 6.9) [13].

Vaso-occlusive processes appear to be the underlying pathophysiological mechanism when APS is associated with complications of pregnancy. These processes can lead to macro and micro-thrombosis in the placental bed. But other mechanisms also play a pathophysiological role, particularly disorders of throphoblast differentiation and invasion with impairment of uteroplacental development [14]. The current hypotheses about the pathogenesis of APS-related complications of pregnancy are summarized in - Table 2 (based on [15]).

A number of different therapeutic concepts have been evaluated with regard to pregnancy outcomes and compared in a meta-analysis. The administration of glucocorticoids and intravenous immunoglobulins (IVIG) did not result in any significant benefit in terms of the rate of live births. Only the combined administration of a prophylactic dose of low-dose acetylsalicylic acid (ASA, 75-100 mg/day) with heparin showed a benefit in terms of pregnancy outcomes in women with prior APS-related pregnancy loss [16]. Another meta-analysis carried out in 2010 confirmed the benefit of the combination therapy compared to monotherapy with ASA [17]. However, most data are from observational studies and there are no studies which directly compare heparin with ASA. The administration of ASA already prior to conception has been successfully used as prophylaxis against abortion in some case series [18], and has been included in guideline recommendations [19]. When women at risk become pregnant, low molecular weight heparin (LMWH) is additionally administered. LMWH has some benefits compared to unfractionated heparin, including more reliable effective concentrations, fewer administrations required because of its longer half-life, and a lower risk of developing heparin-induced thrombopenia type II. However, care should be taken when administering LMWH to patients with impaired kidney function.

It has been suggested in this context that ASA and heparin have potential beneficial effects beyond simple anticoagulation
- Table 1 Classification criteria for antiphospholipid syndrome (based on [6]).

Clinical criteria

- $\geq 1$ venous or arterial case(s) of thrombosis

- 1 or 2 unexplained pregnancy losses of morphologically normal fetuses $>10$ th GW

- $\geq 3$ pregnancy losses $<10$ th GW

- $\geq 1$ late pregnancy loss or preterm birth <34th GW due to placental insufficiency or preeclampsia

Laboratory criteria (present in plasma on two or more occasions measured at least 12 weeks apart)

- Anticardiolipin antibody ( $\operatorname{lgM}, \operatorname{lgG})$ medium to high titer

- Anti-ß2-glycoprotein I antibody (IgM, IgG) high titer

- Lupus anticoagulant

APS is diagnosed if at least one clinical and one laboratory criteria are met.

- Table 2 Relevant pathogenetic mechanisms in APS-related complications of pregnancy (synopsis based on [15]).

Procoagulatory effects

- Activation of plasmatic coagulation (e.g. factor X, prothrombin)

- Increased secretion of tissue factors via TLR 4 in activated endothelial cells and monocytes

- Activation of thrombocytes (expression of glycoprotein Ilb-IIla; increased thromboxane $\mathrm{A} 2$ secretion)

- Inhibition of protein C activity and fibrinolysis

- Disruption of the anticoagulatory annexin A5 shield of the trophoblast and the endometrial endothelium

Inflammatory effects

- Complement activation and deposition in the placenta

- TNF- $\alpha$ secretion through NF-KB activation in monocytes

- Inflammasome activation and secretion of IL1- $\beta$

Direct effects on the placenta

- Inhibition of trophoblast differentiation and invasion (reduced $\beta$-hCG secretion)

- Induced apoptosis of trophoblast cells

- Inhibition of endometrial angiogenesis (VEGF reduction)

TLR 4: Toll-like receptor 4; TNF $\alpha$ : tumor necrosis factor $\alpha$; NF-KB: nuclear factor kappa-light-chain-enhancer of activated B cells; IL1- $\beta$ : interleukin $1 \beta$; $\beta$-hCG: $\beta$-human chorionic gonadotropin; VEGF: vascular endothelial growth factor

such as inhibition of complement activation or the promotion of placental development $[20,21]$.

Particularly women with APS and triple positivity (see above) and a history of prior VTE may benefit from additional treatment strategies combined with ASA and heparin [22]. This was the conclusion of a retrospective analysis of 176 pregnant patients with APS, although only 13 of these pregnant women received additional treatment. It is unclear which of these additional therapies or combinations are effective in the respective setting. The additional administration of IVIG was the most commonly used therapy. 
- Table 3 Thrombophilia and risk of RSA based on meta-analyses.

\begin{tabular}{|c|c|c|c|c|c|}
\hline Thrombophilia & RSA overall & RSA in the 1st & Non-recurrent & \multicolumn{2}{|c|}{ Non-recurrent late miscarriage } \\
\hline Lupus anticoagulant & $\begin{array}{l}15.42(5.90-40.38) \\
{[13]}\end{array}$ & n.s. & $\begin{array}{l}14.28(4.72-43.20) \\
{[28]}\end{array}$ & $2.30(0.81-6.98)[28]$ & $\begin{array}{l}10.59(1.87-59.88) \\
{[10]}\end{array}$ \\
\hline Anticardiolipin antibodies & $3.57(2.26-5.65)[13]$ & $\begin{array}{l}5.05(1.92-14.01) \\
{[28]}\end{array}$ & n.s. & $3.30(1.62-6.70)[28]$ & $\begin{array}{l}4.29(1.34-13.68) \\
{[10]}\end{array}$ \\
\hline ß2-glycoprotein I antibodies & n.s. & $2.12(0.69-6.53)[13]$ & n.s. & \multicolumn{2}{|l|}{$23.46(1.21-455.01)[10]$} \\
\hline $\begin{array}{l}\text { FVL (homozygous and } \\
\text { heterozygous) }\end{array}$ & $3.04(2.16-4.3)[27]$ & $1.91(1.01-3.61)[28]$ & $4.12(1.93-8.81)[28]$ & $3.26(1.82-5.83)[27]$ & $2.06(1.1-3.86)[28]$ \\
\hline Heterozygous PGM G20210A & $2.05(1.18-3.54)[27]$ & $2.70(1.37-5.34)[28]$ & $8.6(2.18-33.95)[28]$ & $2.3(1.09-4.87)[27]$ & $2.66(1.28-5.53)[28]$ \\
\hline Protein S deficiency & $\begin{array}{l}14.72(0.99-218.01) \\
{[27]}\end{array}$ & n.s. & n.s. & $\begin{array}{l}7.39(1.28-42.83) \\
{[27]}\end{array}$ & $\begin{array}{l}20.09(3.7-109.15) \\
{[28]}\end{array}$ \\
\hline Protein C deficiency & $\begin{array}{l}1.57(0.23-10.54) \\
{[27]}\end{array}$ & n.s. & n.s. & \multicolumn{2}{|l|}{$3.05(0.24-38.51)[27]$} \\
\hline Antithrombin deficiency & $0.88(0.17-4.48)[27]$ & n.s. & n.s. & \multicolumn{2}{|l|}{$7.63(0.30-196.36)[28]$} \\
\hline Homozygous MTHFR 677 T & $0.98(0.55-1.72)[27]$ & $0.96(0.44-1.69)[28]$ & n.s. & \multicolumn{2}{|l|}{$1.31(0.89-1.91)[28]$} \\
\hline APC resistance & n.s. & $2.60(1.21-5.59)[28]$ & n.s. & \multicolumn{2}{|l|}{$0.98(0.17-5.55)[28]$} \\
\hline \multicolumn{6}{|c|}{$\begin{array}{l}\text { The confidence interval for the odds ratio was set at 95\%. RSA: recurrent spontaneous abortion; late miscarriage = pooled miscarriages after the 10th [10], } \\
\text { 20th [27] or 24th GW [28]; FVL: factor V Leiden mutation; PGM: prothrombin gene (G20210A) mutation; MTHFR: methylene tetrahydrofolate reductase C677T } \\
\text { mutation; APC resistance: active protein C resistance. Anticardiolipin antibodies: IgG [13,28], IgG/lgM [10]. } \beta 2 \text {-glycoprotein I antibodies: IgG [13], IgG/lgM } \\
\text { [10]. }\end{array}$} \\
\hline
\end{tabular}

The use of hydroxychloroquine in addition to a combination of low-dose ASA and LMWH is recommended to treat pregnant women with SLE and associated APS. Although reliable data on the effect on primary APS are lacking, the additional administration of hydroxychloroquine is recommended for women who continue to suffer miscarriages despite a combination therapy with ASA and LMWH [23].

The role of direct oral anticoagulants as a therapeutic option to treat APS has not yet been sufficiently evaluated [24]. Moreover, the use of direct oral anticoagulants is contraindicated in pregnancy.

For women with APS, pregnancy is a high-risk situation for mother and fetus. Irrespective of the chosen drug therapy, these women must be closely monitored and their care requires the interdisciplinary cooperation of specialists in obstetrics/gynecology, rheumatology and hemostaseology [19].

\section{Hereditary Thrombophilia and Recurrent Spontaneous Abortion}

A number of genetic dispositions, most of which have an autosomal dominant inheritance pattern, have been identified as risk factors for developing VTE. These congenital thrombophilias include inhibitor deficiencies (antithrombin, protein $C$ and protein $\mathrm{S}$ deficiency), activated protein $\mathrm{C}$ resistance based on factor $\mathrm{V}$ Leiden mutation and the prothrombin gene (G20210A) mutation. Mutations of fibrinolysis factors (t-PA, PAI- 1 and factor VII activating protease [FSAP]) and associated hyperhomocysteinemia caused by MTHFR C677T mutation are associated with a signifi- cantly lower risk of VTE. - Fig. 1 schematically illustrates some of the risk factors associated with hereditary thrombophilia which are relevant for the coagulation cascade (based on [25]).

The incidence of these mutations worldwide differs between ethnic groups, resulting in differences in the propensity for thrombogenicity. Based on epidemiological studies it is currently assumed that up to $15 \%$ of the Caucasian population have one of the above-mentioned thrombophilic disorders, of which the heterozygous factor $\mathrm{V}$ R506Q mutation (also known as factor $\mathrm{V}$ Leiden mutation [FVL]) is the most common with $5 \%$. Heterozygous prothrombin (G20210A) gene mutation (PGM) is the second most common mutation and is found in around $2-4 \%$ of the Caucasian population [26].

Two meta-analyses, carried out in 2003 and 2006 respectively, evaluated data from 31 and 79 mostly retrospective case control studies of hereditary thrombophilia and RSA $[27,28]$. The analyses of the association between individual genetic thrombophilias and total RSA, RSA in the 1st trimester of pregnancy and non-recurrent late fetal loss are shown in $>$ Table 3 and compared with antiphospholipid antibodies. The heterogeneity of the data was due to differences in the definition of RSA and the study populations (e.g. week of gestation on inclusion in the study, population size, and ethnicity). An association with RSA has been reported for FVL (pooled for homozygous and heterozygous) and heterozygous $\mathrm{PGM}$, the most common mutations occurring in Caucasian populations. However this risk is lower than that associated with APS. A meta-analysis, carried out in 2010 which only included prospective studies, calculated the pooled odds ratio for all pregnancy losses of women with FVL (absolute risk 4.2\%) compared to healthy controls (absolute risk 3.2\%) as 1.5 (95\% Cl: 1.05-2.19) [29]. Patients with 


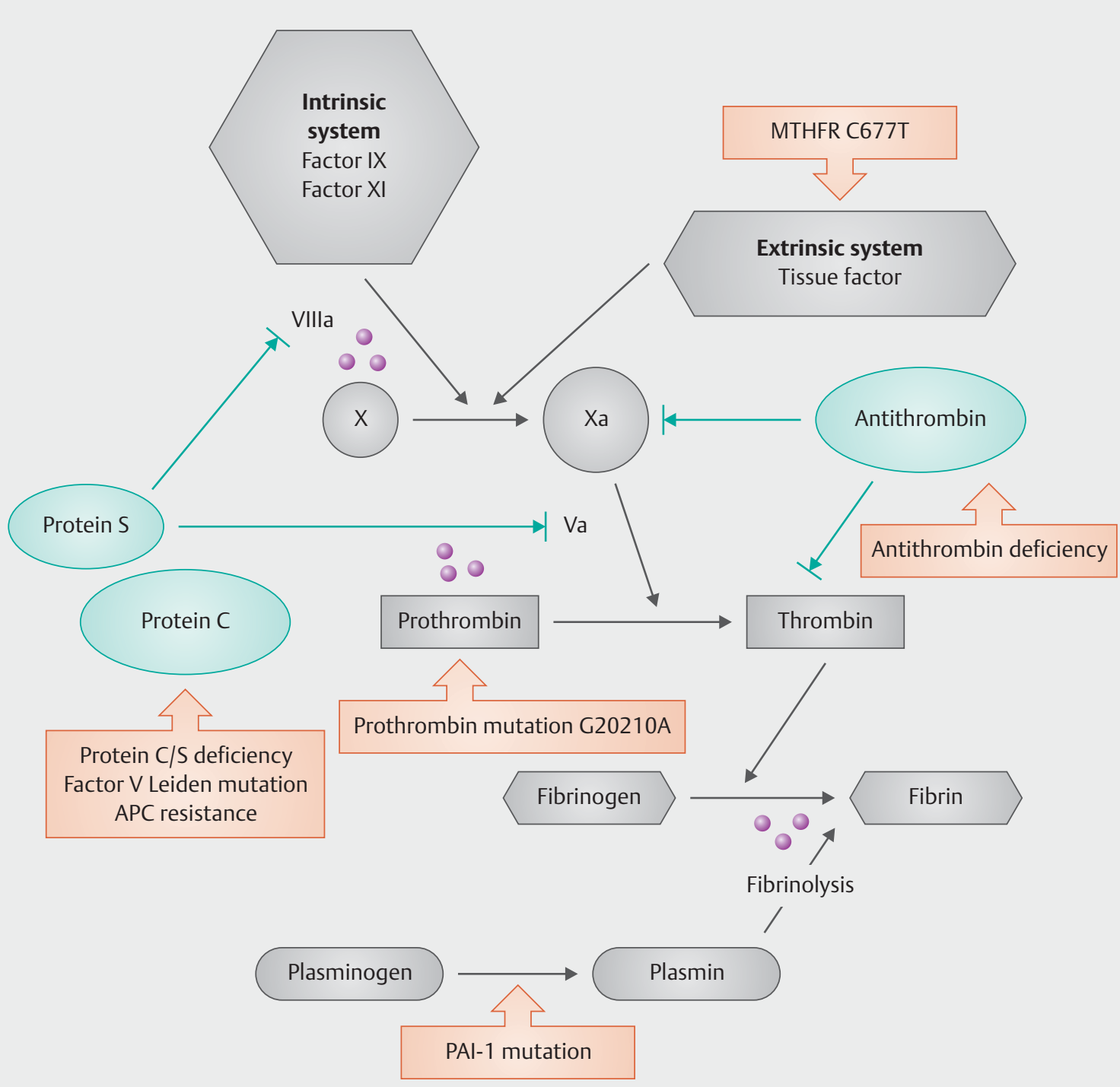

- Fig. 1 Plasmatic coagulation, fibrinolysis and thrombophilia (modified according to [25]). Activation of the coagulation cascade via extrinsic or intrinsic systems leads to factor $X$ activation. This then leads to cleavage of factor II (prothrombin) and to the development of thrombin. Antithrombin and protein $\mathrm{C} / \mathrm{S}$ function here as inhibitory factors (indicated in green in the illustration). Red identifies the most common types of hereditary thrombophilia. Pink circles stand for potential thrombophilic mechanisms in APS (e.g. through interactions of the antibodies with factor $X$ or prothrombin; inhibition of fibrinolysis). In addition (not shown here), the activation of endothelial cells and thrombocytes play a pathogenetic role in APS. MTHFR C677T: methylene tetrahydrofolate reductase polymorphism, APC: activated protein C, PAI-1: plasminogen activator inhibitor-1.

antithrombin and protein C deficiency and homozygous MTHFR 677T mutation do not appear to have an increased risk of RSA.

It should be noted that, because of their rarity, there are almost no data available for significantly rarer and highly thrombophilic constellations such as homozygous mutations (both FVL mutation and PGM G20210A) or complex combined hereditary thrombophilia. The current body of data on the association between late miscarriages (after the 24th GW) and the presence of antithrombin or protein $C$ deficiency is also insufficient.

In addition to the risk of miscarriage a correlation between hereditary thrombophilia and other placenta-related complications is also currently being discussed $[29,30]$. The available data are shown in $>$ Table 4.
The first studies on the prophylactic administration of heparin to women with hereditary thrombophilia and RSA appeared to be promising based on the rate of live births. But these results, which were predominantly obtained from observational studies, were not confirmed by recently carried out prospective randomized controlled studies. A meta-analysis of data from randomized controlled studies was recently published [31]. In their meta-analysis, Skeith et al. analyzed the pooled data of 483 pregnant women with different types of hereditary thrombophilia evaluated in eight prospective randomized controlled studies, some of which were also placebo controlled. No difference was found with regard to the reduction of late pregnancy losses (defined as loss after 10th GW, level of evidence 1b) or recurrent early pregnancy losses 
- Table 4 Thrombophilia and placenta-related complications of pregnancy based on meta-analyses.

\begin{tabular}{|c|c|c|c|c|c|c|}
\hline Thrombophilia & \multicolumn{2}{|l|}{ Preeclampsia } & \multirow{2}{*}{\multicolumn{2}{|c|}{$\begin{array}{l}\text { Premature placental separation } \\
0.26(0.01-4.56)[10]\end{array}$}} & \multirow{2}{*}{\multicolumn{2}{|c|}{$\begin{array}{l}\text { Growth retardation } \\
4.65(1.29-16.71)[10]\end{array}$}} \\
\hline Lupus anticoagulant & \multirow{2}{*}{$\begin{array}{l}1.45(0.70- \\
4.61)[28] \\
2.73(1.65- \\
4.51)[28]\end{array}$} & \multirow{2}{*}{$\begin{array}{l}2.34(1.18- \\
4.64)[10] \\
1.52(1.05- \\
2.20)[10]\end{array}$} & & & & \\
\hline $\begin{array}{l}\text { Anticardiolipin anti- } \\
\text { bodies }\end{array}$ & & & $\begin{array}{l}1.42(0.42- \\
4.77)[28]\end{array}$ & $\begin{array}{l}1.30(0.35- \\
4.78)[10]\end{array}$ & $\begin{array}{l}6.91(2.70- \\
17.68)[28]\end{array}$ & $\begin{array}{l}1.97(0.19- \\
19.96)[10]\end{array}$ \\
\hline $\begin{array}{l}\text { Anti- } \beta 2 \text { GP1 } \lg G / \lg M \\
\text { antibodies }\end{array}$ & \multicolumn{2}{|c|}{$19.14(6.34-57.77)[10]$} & \multicolumn{2}{|c|}{$2.64(0.14-50.63)[10]$} & \multicolumn{2}{|c|}{$20.03(4.59-87.43)[10]$} \\
\hline FVL (homozygous) & $\begin{array}{l}1.87(0.44- \\
7.88)[28]\end{array}$ & $\begin{array}{l}1.23(0.89- \\
1.70)^{*}[29]\end{array}$ & $\begin{array}{l}8.43(0.41- \\
171.20)[28]\end{array}$ & $\begin{array}{l}1.85(0.92- \\
3.70)^{*}[29]\end{array}$ & $\begin{array}{l}4.64(0.19- \\
115.68)[28]\end{array}$ & $\begin{array}{l}1.00(0.80- \\
1.25)^{*}[29]\end{array}$ \\
\hline FVL (heterozygous) & $\begin{array}{l}2.19(1.46- \\
3.27)[28]\end{array}$ & $\begin{array}{l}1.23(0.89- \\
1.70)^{*}[29]\end{array}$ & $\begin{array}{l}4.70(1.13- \\
19.59)[28]\end{array}$ & $\begin{array}{l}1.85(0.92- \\
3.70)^{*}[29]\end{array}$ & $\begin{array}{l}2.68(0.59- \\
12.13)[28]\end{array}$ & $\begin{array}{l}1.00(0.80- \\
1.25)^{*}[29]\end{array}$ \\
\hline $\begin{array}{l}\text { Heterozygous PGM } \\
\text { G20210A }\end{array}$ & $\begin{array}{l}2.54(1.52- \\
4.23)[28]\end{array}$ & $\begin{array}{l}1.25(0.79- \\
1.99)[29]\end{array}$ & $\begin{array}{l}7.71(3.01- \\
19.76)[28]\end{array}$ & $\begin{array}{l}2.02(0.81- \\
5.02)[29]\end{array}$ & $\begin{array}{l}2.92(0.62- \\
13.70)[28]\end{array}$ & $\begin{array}{l}1.25(0.92-1.70) \\
{[29]}\end{array}$ \\
\hline Protein C deficiency & \multicolumn{2}{|c|}{$5.15(0.26-102.22)[28]$} & \multicolumn{2}{|c|}{$5.93(0.23-151.58)[28]$} & \multicolumn{2}{|l|}{ n.s. } \\
\hline Protein S deficiency & \multicolumn{2}{|c|}{$2.83(0.76-10.57)[28]$} & \multicolumn{2}{|c|}{$2.11(0.47-9.34)[28]$} & \multicolumn{2}{|l|}{ n.s. } \\
\hline $\begin{array}{l}\text { Antithrombin } \\
\text { deficiency }\end{array}$ & \multicolumn{2}{|c|}{$3.89(0.16-97.19)[28]$} & \multicolumn{2}{|c|}{$1.08(0.06-18.12)[28]$} & \multicolumn{2}{|l|}{ n.s. } \\
\hline $\begin{array}{l}\text { Homozygous MTHFR } \\
677 \mathrm{~T}\end{array}$ & \multicolumn{2}{|c|}{$1.37(1.07-1.76)[28]$} & \multicolumn{2}{|c|}{$1.47(0.40-5.35)[28]$} & \multicolumn{2}{|c|}{$1.24(0.84-1.82)[28]$} \\
\hline APC resistance & \multicolumn{2}{|l|}{ n.s. } & \multicolumn{2}{|c|}{$2.60(1.21-5.59)[28]$} & \multicolumn{2}{|c|}{$0.98(0.17-5.55)[28]$} \\
\hline
\end{tabular}

(defined as $>2$ pregnancy losses before the 10th GW, level of evidence $2 \mathrm{~b}$ ) between women who received LMWH and those who did not. This meta-analysis also has some limitations, mainly due to the heterogeneous design of the studies included in the metaanalysis, the inconsistent definitions of RSA in the individual studies and the inconsistent differentiation between early and late pregnancy loss. Some of the studies used ASA in the control arm, and it is therefore not possible to exclude the possibility that ASA was a confounding variable. Rare homozygous or combined gene variants are also underrepresented in this study. Researchers are awaiting the results of other prospective randomized controlled studies such as the currently ongoing ALIFE2 trial [32] to evaluate the body of evidence and resolve some of the open issues.

The results of a meta-analysis published in 2016 on recurrent placenta-related complications and the prophylactic administration of heparin were similar. The evaluation of a total of 401 patients with genetic thrombophilia did not find a general benefit from administering LMWH [33]. Only a subgroup analysis of patients with premature placental separation showed a benefit for the prophylactic use of LMWH. The cohorts, both from single-center and multicenter studies, were also extremely heterogeneous.

There is a clear recommendation that patients with a prior history of preeclampsia or fetuses with intrauterine growth retardation should receive prophylactic ASA, irrespective of any underlying maternal thrombophilia [34]. According to more recent data, the risk of preeclampsia can be reduced by commencing ASA intake as soon as possible (before the 16th week of pregnancy) and administering ASA doses of at least $100 \mathrm{mg} /$ day [35]. But the administration of ASA is not generally recommended as a prophy- laxis against spontaneous abortion [36]. Further studies will be needed in future to determine to what extent ASA has a dose-dependent effect on women known to have APS.

\section{National and International Guidelines on the Diagnosis and Prophylactic Treatment of Pregnancy Loss due to RSA and Maternal Thrombophilia}

The data collected over the last decade are controversial and the recommendations issued by various international guidelines show similar differences. A comparison of German [37], American [38] and British [39] guidelines on the diagnosis and treatment of RSA and thrombophilia is shown in > Table 5. These guidelines were compiled between 2011 and 2015 and represent the consensus of various panels of experts; the reported levels of evidence correspond to the data available at the respective time of compilation.

All of the recommendations are agreed that in the event of RSA and other complications of pregnancy as defined by the APS classification criteria, affected women should be screened for antiphospholipid antibodies and LA. For women with a confirmed diagnosis of APS, the recommendation is to administer low-dose ASA and a prophylactic dose of LMWH from the time of the positive pregnancy test until at least 6 weeks post partum.

The guidelines unanimously reject any general prophylactic administration of LMWH to treat 1st trimester RSA due to maternal hereditary thrombophilia. As regards pregnancy losses from 
- Table 5 Comparison of recommendations in the most recent German, American and British guidelines on RSA (<20th week of pregnancy) and maternal thrombophilia without prior VTE.

\begin{tabular}{|c|c|c|c|}
\hline RSA without VTE & German guideline [37] & American guideline [38] & British guideline [39] \\
\hline $\begin{array}{l}\text { Screening for APS (LA, anticardio- } \\
\text { lipin antibodies IgG and IgM, anti- } \beta 2 \\
\text { GP1 antibodies } \lg G \text { and } \lg M \text { ) }\end{array}$ & Yes & Yes (level of evidence 1B) & Yes (level of evidence D) \\
\hline $\begin{array}{l}\text { Screening for hereditary } \\
\text { thrombophilia }\end{array}$ & $\begin{array}{l}\text { AT activity, APC resis- } \\
\text { tance/FVL, PGM }\end{array}$ & No (level of evidence 2C) & $\begin{array}{l}\text { Only if the reason for pregnancy loss from } \\
\text { the } 2 \text { nd trimester is unclear: FVL, PGM, } \\
\text { protein S deficiency (level of evidence D) }\end{array}$ \\
\hline \multicolumn{4}{|l|}{$\begin{array}{l}\text { Prophylactic administration } \\
\text { of medication }\end{array}$} \\
\hline Hereditary thrombophilia & $\begin{array}{l}\text { No administration outside } \\
\text { clinical studies }\end{array}$ & No (level of evidence 2C) & $\begin{array}{l}\text { LMWH for pregnancy losses from the } \\
\text { 2nd trimester (level of evidence A) }\end{array}$ \\
\hline APS & Low-dose ASA and LMWH & $\begin{array}{l}\text { Low-dose ASA and LMWH } \\
\text { (level of evidence 1B) }\end{array}$ & $\begin{array}{l}\text { Low-dose ASA and LMWH } \\
\text { (level of evidence B) }\end{array}$ \\
\hline
\end{tabular}

- Table 6 Recommendation for LMWH administration during pregnancy if maternal thrombophilia is present.

\begin{tabular}{|c|c|c|}
\hline & Recurrent early pregnancy loss/late pregnancy loss & Increased maternal risk for VTE \\
\hline Hereditary thrombophilia & o & es \\
\hline APS & \multicolumn{2}{|c|}{$\begin{array}{l}75-100 \mathrm{mg} \text { ASA/day, optimally initiated before conception, combined with LMWH from the time of a positive } \\
\text { pregnancy test until } 6 \text { weeks post partum }{ }^{1}\end{array}$} \\
\hline \multicolumn{3}{|c|}{$\begin{array}{l}\text { LMWH: low molecular weight heparin; VTE: venous thromboembolism; APS: antiphospholipid syndrome. } \\
1 \text { During pregnancy, blood pressure, proteinuria and maternal weight from the 16th-20th GW must be monitored along with monthly monitoring of fetal } \\
\text { growth and placental perfusion. }\end{array}$} \\
\hline \multicolumn{3}{|c|}{$\begin{array}{l}\text { Osteoporosis prophylaxis must be combined with monitoring thrombocyte counts during LMWH treatment in accordance with the AWMF S3 guideline [41] } \\
\text { (between the 5th to } 15 \text { th day after the start of LMWH; a drop of the thrombocyte count to less than } 50 \% \text { of the initial count is suspicious for heparin-induced } \\
\text { thrombopenia type Ila, which would necessitate the immediate cessation of heparin therapy). }\end{array}$} \\
\hline
\end{tabular}

the 2 nd trimester of pregnancy, the British guideline recommends investigating the patient to determine whether any hereditary thrombophilia is present as well as the prophylactic use of LMWH. The latter recommendation is not sufficiently supported by the meta-analysis published in 2016 [31]. A general diagnostic workup for maternal hereditary thrombophilia in case of RSA will no longer be recommended in the soon-to-be-published update of the German guideline (personal communication, E. Schleußner).

\section{VTE Prophylaxis for Maternal Thrombophilia in Pregnancy}

From a hemostaseological perspective, pregnancy is per se a physiological condition of increased procoagulatory activity. The risk of pregnant women developing VTE is 5 times higher throughout the entire pregnancy compared to non-pregnant women; the risk is 20-fold higher in the postnatal period [40]. Delivery by C-section additionally increases the risk of VTE between 2- and 4-fold compared to vaginal delivery [41]. In industrialized countries, the incidence of pulmonary embolism is 1-1.5 per
100000 births, making it the most common cause of maternal death post partum [42]. Women receiving hormones (e.g., for reproductive treatment) have a generally increased risk of VTE.

Irrespective of recurrent pregnancy losses or other complications of pregnancy the individual maternal risk of VTE (disposition and exposition) determines whether or not drug treatment as prophylaxis against thrombosis is necessary and therefore whether heparin administration is indicated during pregnancy. Important factors for an increased risk of VTE include prior VTE or a positive familial history of VTE, certain complications of pregnancy such as exsiccosis/hyperemesis, hospitalization, assisted reproduction, and overweight. The AWMF S3 guideline recommends heparin therapy during pregnancy, particularly when highly thrombophilic mutations (homozygous FVL mutation, antithrombin deficiency, complex combined variants) are present, because of the increased maternal risk of VTE [41].

- Table 6 summarizes decision-making on the use of low molecular weight heparin to treat pregnant patients with thrombophilia. 


\section{Conclusion}

Screening for antiphospholipid antibodies including LA is recommended in cases with recurrent spontaneous abortion and/or placenta-related complications of pregnancy. APS is a serious acquired thrombophilia and represents a clear indication for the administration of low-dose ASA prior to conception combined with prophylactic doses of LMWH from the start of pregnancy (level of evidence 1b).

Based on the currently available studies, recurrent spontaneous abortion in women with maternal hereditary thrombophilia is not an indication for the prophylactic administration of LMWH in subsequent pregnancies (level of evidence $2 b$ for RSA < 10th GW, 1b for pregnancy losses after the 10th GW).

According to the current guidelines, the maternal risk for thromboembolic events determines whether non-drug-based or drug-based VTE prophylaxis is indicated, e.g. with low molecular weight heparin. In addition to maternal disposition, other VTE factors such as immobilization, hospitalization, dehydration due to hyperemesis, assisted reproduction or overweight are also clinically relevant for the assessment of maternal risk and the decision whether VTE prophylaxis is indicated. Based on the currently available data, there is insufficient evidence that women who have recurrent spontaneous abortion should undergo broad screening for hereditary thrombophilia.

Interdisciplinary cooperation between specialists in obstetrics/ gynecology, rheumatology and hemostaseology is important to ensure optimal management of patients.

\section{Conflict of Interest}

The authors declare that they have no conflict of interest.

\section{References}

[1] WHO. Recommended definitions, terminology and format for statistical tables related to the perinatal period and use of a new certificate for cause of perinatal deaths. Acta Obstet Gynecol Scand 1977; 56: 247253

[2] Rai R, Regan L. Recurrent miscarriage. Lancet 2006; 368: 601-611

[3] Practice Committee of American Society for Reproductive Medicine. Definitions of infertility and recurrent pregnancy loss: a committee opinion. Fertil Steril 2013; 99: 63

[4] Practice Committee of the American Society for Reproductive Medicine. Evaluation and treatment of recurrent pregnancy loss: a committee opinion. Fertil Steril 2012; 98: 1103-1111

[5] Specker C. Antiphospholipid syndrome. Z Rheumatol 2016; 75: 570-574

[6] Miyakis S, Lockshin MD, Atsumi T et al. International consensus statement on an update of the classification criteria for definite antiphospholipid syndrome (APS). J Thromb Haemost 2006; 4: 295-306

[7] Cervera R, Piette JC, Font J et al. Antiphospholipid syndrome: clinical and immunologic manifestations and patterns of disease expression in a cohort of 1,000 patients. Arthritis Rheum 2002; 46: 1019-1027

[8] Rai $\mathrm{R}$, Clifford $\mathrm{K}$, Cohen $\mathrm{H}$ et al. High prospective fetal loss rate in untreated pregnancies of women with recurrent miscarriage and antiphospholipid antibodies. Hum Reprod 1995; 10: 3301-3304
[9] Chighizola CB, Andreoli L, de Jesus GR et al. The association between antiphospholipid antibodies and pregnancy morbidity, stroke, myocardial infarction, and deep vein thrombosis: a critical review of the literature. Lupus 2015; 24: 980-984

[10] Abou-Nassar K, Carrier M, Ramsay T et al. The association between antiphospholipid antibodies and placenta mediated complications: a systematic review and meta-analysis. Thromb Res 2011; 128: 77-85

[11] Andreoli L, Chighizola CB, Banzato A et al. Estimated frequency of antiphospholipid antibodies in patients with pregnancy morbidity, stroke, myocardial infarction, and deep vein thrombosis: a critical review of the literature. Arthritis Care Res (Hoboken) 2013; 65: 1869-1873

[12] Yelnik CM, Laskin CA, Porter TF et al. Lupus anticoagulant is the main predictor of adverse pregnancy outcomes in aPL-positive patients: validation of PROMISSE study results. Lupus Sci Med 2016; 3: e000131

[13] Opatrny L, David M, Kahn SR et al. Association between antiphospholipid antibodies and recurrent fetal loss in women without autoimmune disease: a metaanalysis. J Rheumatol 2006; 33: 2214-2221

[14] Viall CA, Chamley LW. Histopathology in the placentae of women with antiphospholipid antibodies: a systematic review of the literature. Autoimmun Rev 2015; 14: 446-471

[15] Ostensen M, Andreoli L, Brucato A et al. State of the art: reproduction and pregnancy in rheumatic diseases. Autoimmun Rev 2015; 14: 376386

[16] Empson M, Lassere M, Craig J et al. Prevention of recurrent miscarriage for women with antiphospholipid antibody or lupus anticoagulant. Cochrane Database Syst Rev 2005; (2): CD002859

[17] Mak A, Cheung MW, Cheak AA et al. Combination of heparin and aspirin is superior to aspirin alone in enhancing live births in patients with recurrent pregnancy loss and positive anti-phospholipid antibodies: a metaanalysis of randomized controlled trials and meta-regression. Rheumatology (Oxford) 2010; 49: 281-288

[18] Bouvier S, Cochery-Nouvellon E, Lavigne-Lissalde G et al. Comparative incidence of pregnancy outcomes in treated obstetric antiphospholipid syndrome: the NOH-APS observational study. Blood 2014; 123: 404413

[19] Andreoli L, Bertsias GK, Agmon-Levin N et al. EULAR recommendations for women's health and the management of family planning, assisted reproduction, pregnancy and menopause in patients with systemic lupus erythematosus and/or antiphospholipid syndrome. Ann Rheum Dis 2017; 76: 476-485

[20] Girardi G, Redecha P, Salmon JE. Heparin prevents antiphospholipid antibody-induced fetal loss by inhibiting complement activation. Nat Med 2004; 10: 1222-1226

[21] Alvarez AM, Balcázar N, San Martín S et al. Modulation of antiphospholipid antibodies-induced trophoblast damage by different drugs used to prevent pregnancy morbidity associated with antiphospholipid syndrome. Am J Reprod Immunol 2017; 77: e12634

[22] Ruffatti A, Salvan E, Del Ross T et al. Treatment strategies and pregnancy outcomes in antiphospholipid syndrome patients with thrombosis and triple antiphospholipid positivity. A European multicentre retrospective study. Thromb Haemost 2014; 112: 727-735

[23] Sciascia S, Branch DW, Levy RA et al. The efficacy of hydroxychloroquine in altering pregnancy outcome in women with antiphospholipid antibodies. Evidence and clinical judgment. Thromb Haemost 2016; 115: 285-290

[24] Cohen H, Hunt B], Efthymiou M et al. Rivaroxaban versus warfarin to treat patients with thrombotic antiphospholipid syndrome, with or without systemic lupus erythematosus (RAPS): a randomised, controlled, open-label, phase 2/3, non-inferiority trial. Lancet Haematol 2016; 3: e426-e436

[25] Willeke A, Gerdsen F, Bauersachs RM et al. Rationelle Thrombophiliediagnostik. Deutsches Ärzteblatt 2002; 31-32: 2111-2118 
[26] Roberts LN, Patel RK, Arya R. Venous thromboembolism and ethnicity. Br J Haematol 2009; 146: 369-383

[27] Rey E, Kahn SR, David M et al. Thrombophilic disorders and fetal loss: a meta-analysis. Lancet 2003; 361: 901-908

[28] Robertson L, Wu O, Langhorne $P$ et al. Thrombophilia in pregnancy: a systematic review. $\mathrm{Br}$ J Haematol 2006; 132: 171-196

[29] Rodger MA, Betancourt MT, Clark P et al. The association of factor V Leiden and prothrombin gene mutation and placenta-mediated pregnancy complications: a systematic review and meta-analysis of prospective cohort studies. PLoS Med 2010; 7: e1000292

[30] Baumann K, Beuter-Winkler P, Hackethal A et al. Maternal factor V Leiden and prothrombin mutations do not seem to contribute to the occurrence of two or more than two consecutive miscarriages in Caucasian patients. Am J Reprod Immunol 2013; 70: 518-521

[31] Skeith L, Carrier M, Kaaja R et al. A meta-analysis of low-molecularweight heparin to prevent pregnancy loss in women with inherited thrombophilia. Blood 2016; 127: 1650-1655

[32] de Jong PG, Quenby S, Bloemenkamp KW et al. ALIFE2 study: low-molecular-weight heparin for women with recurrent miscarriage and inherited thrombophilia-study protocol for a randomized controlled trial. Trials 2015; 16: 208

[33] Rodger MA, Gris JC, de Vries JIP et al. Low-molecular-weight heparin and recurrent placenta-mediated pregnancy complications: a meta-analysis of individual patient data from randomised controlled trials. Lancet 2016; 388: 2629-2641

[34] Bujold E, Roberge S, Lacasse Y et al. Prevention of preeclampsia and intrauterine growth restriction with Aspirin started in early pregnancy. Obstet Gynecol 2010; 116: 402-414
[35] Roberge S, Nicolaides K, Demers S et al. The role of aspirin dose on the prevention of preeclampsia and fetal growth restriction: systematic review and meta-analysis. Am J Obstet Gynecol 2017; 216: 110-120.e6

[36] Schisterman EF, Silver RM, Lecher LL et al. Preconception low-dose aspirin and pregnancy outcomes: results from the EAGeR randomised trial. Lancet 2014; 384: 29-36

[37] Toth B, Würfel W, Bohlmann MK et al. Recurrent miscarriage: diagnostic and therapeutic procedures. Guideline of the DGGG (S1-Level, AWMF Registry No.015/050, December 2013). Geburtsh Frauenheilk 2015; 75: 1117-1129

[38] Bates SM, Greer IA, Middeldorp S et al. VTE, thrombophilia, antithrombotic therapy, and pregnancy: Antithrombotic Therapy and Prevention of Thrombosis, 9th ed: American College of Chest Physicians EvidenceBased Clinical Practice Guidelines. Chest 2012; 141: e691S-e736S

[39] Gynaecologists, RCOG. The investigation and treatment of couples with recurrent firsttrimester and second-trimester miscarriage. RCOG Greentop Guideline No. 17, 2011. Last update April 2011. Online: www.nice. org.uk/accreditation

[40] Heit J, Kobbervig CE, James AH et al. Trends in the incidence of venous thromboembolism during pregnancy or postpartum: a 30-year population-based study. Ann Intern Med 2005; 143: 697-706

[41] Encke A, Haas S, Kopp I et al. S3-Leitlinie Prophylaxe der venösen Thromboembolie (VTE). AWMF 2015. Online: http://www.awmf.org/leitlinien/ detail/I/003-001.html; last access: 15.10.2015

[42] Marik PE, Plante LA. Venous thromboembolic disease and pregnancy. N Engl J Med 2008; 359: 2025-2033 